О.Б. Аскарова (доц. УГАТУ, г.Уфа)

\title{
РАЗВИТИЕ ФРАЗЕОЛОГИЧЕСКОГО ЛЕКСИКОНА ПРИ ЕСТЕСТВЕННОМ И УЧЕБНОМ БИЛИНГВИЗМЕ
}

B cтатье рассматриваются вопросы развития билингвизма. $B$ направленном ассоциативном эксперименте респонденть-билингвы воспроизводили устойчивые словосочетания русского и английского языков по их первому и второму компоненту. Полученные результаты показали различия в степени воспроизводимости в двух группах испытуемых. Исследование выявило некоторые факторы, влияющие на усвоение фразеологизмов этих двух языков в условиях естественного и учебного билингвизма.

Ключевые слова: ассоциативный эксперимент, фразеологизм, стимул, реакиия, воспроизведение, билингвизм, естественный, искусственный, психолингвистический анализ

The article is devoted to native and instructed bilingualism. The task in the directed associative experiments was to reproduce Russian and English idiomatic expressions with the help of their first and second components. The results obtained showed certain differences characteristic for the two groups of respondents. The investigation revealed some factors affecting peculiarities in mastering the second language phraseological units and their cultural background.

Key words: association experiments, stimuli, reactions, phraseological units, reproduction, bilingualism, natural, instructed, psycholinguistic analysis

В условиях многовекторного развития современного общества языковая личность находится на пересечении действия разных социолингвистических и психолингвистических факторов. Полиэтничность нашего региона в сочетании с многоязычием и мультикультуральностью дает богатый материал 
для исследования особенностей речевой деятельности и языковой способности обучаемых при овладении неродным вторым языком и при изучении иностранных языков. «Переход с одного языка на другой(иностранный) с психолингвистической точки зрения есть - в наиболее общем случае - смена правил перехода от программы к ее реализации [Леонтьев,2005:222]

«Содержание знаков естественного языка (в особенности его образных средств) пронизано разного рода (меж)сенсорными и (меж)перцептивными связями и ассоциациями, которые отражают на языковом уровне специфику работы психоневрологической и (или нейронной) системы человека.[ Зыкова, 2017:290] Материалом для нашего исследования послужили словосочетания русского и английского языков в диапазоне от свободных переменных словосочетаний до фразеологических единиц. Классификация УСС русского языка в соответствии с нарастанием идиоматизации была разработана на материале направленного психолингвистического эксперимента через объяснение содержания ФЕ. Представляется логичным и закономерным исследование языкового сознания билингвов через ассоциативный эксперимент [Аскарова, 2018: 19-23]

На первом этапе проводился направленный ассоциативный эксперимент со студентами УГАТУ, уроженцами разных районов РБ, владеющими как родным, так и русским языком. Важно отметить, что они достаточно рано начинают осваивать русский в качестве второго языка общения и обучения. На следующем этапе проводились направленные ассоциативные эксперименты со студентами и выпускниками факультетов иностранной языковой специализации вузов РБ.

Словосочетания-стимулы поделены на пять типов по упомянутой классификации следующим образом:

1) свободные словосочетания ЧАШКА ЧАЯ, А СUP OF TEA

2) фразеологические терминологические выражения ЖЕЛЕЗНАЯ ДОРОГА, КЕY SECTOR

3) фразеологические сочетания БАБЬЕ ЛЕTO, INDIAN SUMMER

4) фразеологические единства БРОСИТЬ КАМЕНЬ, ТО PULL ONE'S LEG

5) фразеологические сращения 


\section{СОБАКУ СЪЕЛ, A SKELETON IN THE CUPBOARD}

Поскольку целью нашего исследования было выяснение условий воспроизведения УСС по первому и по второму элементу, стимулы1 и стимулы2 предъявлялись разным группам испытуемых, чтобы предупредить возможные догадки о задачах эксперимента и предотвратить подыгрывание экспериментатору. Такая разновидность эксперимента была предложена Т.М. Дридзе для изучения языковых клише [Дридзе,1980: 145]. Полученные ответы анализировались отдельно по первому и второму стимулу.

\begin{tabular}{|c|l|l|l|l|}
\hline & Стимул 1 & \% & Стимул 2 & \% \\
\hline 1. & чашка & 73,9 & чая & 43,8 \\
\hline 2. & железная & 62,5 & дорога & 0 \\
\hline 3. & выйти & & $\begin{array}{l}\text { на } \\
\text { орбиту }\end{array}$ & 7,4 \\
\hline 4. & бабье & 93,8 & лето & 0 \\
\hline 5. & человек & 18,8 & $\begin{array}{l}\text { в } \\
\text { футляре }\end{array}$ & 14,8 \\
\hline 6. & мыльный & 56,5 & пузырь & 68,8 \\
\hline 7. & бросить & 4,3 & камень & 18,8 \\
\hline 8. & море (по) & 95,7 & $\begin{array}{l}\text { по } \\
\text { колено }\end{array}$ & 56,3 \\
\hline 9. & подложить & 12,5 & свинью & 11,1 \\
\hline 10 & собаку & 8,7 & съел & 12,5 \\
\hline
\end{tabular}

При несформированности полноценного автоматизма семантических и других типов языковых связей в осваиваемом языке возникает интерференция, когда человек использует навыки родного языка. Управляемое овладение иностранным языком в условиях систематического вузовского и школьного обучения осуществляется также «через ступень опосредованного владения иностранным языком; опосредующим звеном здесь выступает «родная» система правил реализации программы». При этом используется межъязыковая сопоставительная модель, а целью является речевой навык с такими параметрами, как бессознательность, полная автоматичность, соответствие норме 
языка, нормальная скорость выполнения речевой операции и устойчивость. [Леонтьев, 2005:221-223]

\begin{tabular}{|l|l|l|l|l|}
\hline & Стимул 1 & \% & Стимул 2 & $\%$ \\
\hline 1. & a cup & 33 & of tea & 90 \\
\hline 2. & art(s) & 0 & gallery & 61 \\
\hline 3. & fit & 0 & for duty & 0 \\
\hline 4. & key & 0 & sector & 0 \\
\hline 5. & Indian & 10 & summer & 10 \\
\hline 6. & to talk & 10 & shop & 0 \\
\hline 7. & wet & 20 & blanket & 17,6 \\
\hline 8. & to pull & 20 & one's leg & 20 \\
\hline 9. & pretty & 0 & $\begin{array}{l}\text { kettle of } \\
\text { fish }\end{array}$ & 11,7 \\
\hline 10. & a skeleton & 0 & $\begin{array}{l}\text { in the } \\
\text { cupboard }\end{array}$ & 11,7 \\
\hline
\end{tabular}

Сравнивая результаты двух этапов исследования, можно заметить, что в первом эксперименте восстановление искомых словосочетаний-стимулов происходило успешнее, чем во втором эксперименте с английскими стимулами. Средний показатель по стимулу1 составил 43\% и $39 \%$ в первом и втором эксперименте соответственно. Это подтверждает тезис о том, что первое слово выполняет роль «сигнального» фрагмента. Средний показатель воспроизведения по стимулу $2-23 \%$ и $21 \%$.

По разрядам фразеологической классификации была отмечена высокая степень воспроизведения искомых свободных словосочетаний. По второму разряду фразеологических или терминологических выражений степень восстановления у первой группы информантов была достаточно высокой, а во второй группе информантов эти выражения не были восстановлены, вероятно, по двумя причинам. Во-первых, для данной группы испытуемых фразеологические выражения явились «штампом» сознания или клише с нулевым значением. Во-вторых, есть вероятность того, что эти сочетания не вошли в их индивидуальный англоязычный культурный лексикон. Фразеологические сочетания воспроизводились в обеих группах испытуемых, но один из компонентов с менее маркированной 
семантикой не приводил к вспоминанию искомого сочетания. Фразеологические единства, характеризуемые прямым и переносным значением в зависимости от контекста, также показали тесную ассоциативную связь между компонентами сочетания. Фразеологические сращения с максимальной идиоматизацией воспроизводились со средним показателем $10 \%$.

Корпус полученных реакций в соответствии со стратегиями восстановления и характеристиками лексикосемантического наполнения делится на следующие типы:

1. свободные словосочетания с переменными элементами:

КАМЕНЬ - красивый

МЫЛЬНЫЙ- палеи

SUMMER - holiday
СЪЕЛ - кашу

ЧАШКА - мокрая

IN THE CUPBOARD cutlery

BLANKET - red

SECTOR - first

Переменные окказиональные сочетания в любом языке образуются по грамматическим правилам и заданным синтаксическим моделям, а лексическое наполнение зависит от выражаемой мысли и описываемой ситуации.

2. а) Терминологические сочетания и клишированные выражения, которые имеют регулярное языковое оформление:

ЧАШКА - Петри

ВЫЙТИ - на новый уровень
$K E Y-$ words
SHOP - assistant
SHOP - coffee
SECTOR - fan

б) Речевые формулы, названия, заголовки и цитаты:

КАМЕНЬ - ножницы, бумага

ЧЕЛОВЕК В - теле

ЧЕЛОВЕК - в футляре

PRETTY - woman

SUMMER - time

GALLERY - Tate, Tretyakov

В устойчивых узуальных словосочетаниях заранее задана не только грамматическая модель, но и конкретный лексический состав. Такие словосочетания - это не спонтанные речевые комбинации знаков, а особые сложные знаки, которые хранятся в готовом виде в памяти носителей языка.

3. фразеологические единицы, имеющие яркую языковую форму и четкую стилистическую окраску:

КАМЕНЬ - преткновения, философский SHOP - bull in the China

БАБЬЕ - лето 
WET - get... to the skin

БРОСИТЬ монету

Устойчивость и воспроизводимость фразеологических словосочетаний, с одной стороны, может быть обусловлена очень узкой, избирательной сочетаемостью слова-стимула с другими словами- вплоть до единичной сочетаемости. С другой стороны, причина устойчивости чаще всего связана с семантическим сдвигом значения в пределах словосочетания. Упомянутый сдвиг затрагивает либо один из компонентов сочетания, либо наблюдается общий сдвиг значения, затрагивающий все компоненты.

Рассмотрим ту часть ответов, которая выходит за рамки классификационных категорий и «именно неправильности... освещают недоступный внешнему наблюдению процесс овладения языком.» [Тер-Минасова, 2007: 98]

1.Единицы принятия решения колебались от части сложного слова до целой фразы:

$$
\begin{array}{lc}
\text { ЧАЯ - Нет } & \text { СВИНЬЮ - не ем } \\
\text { KEY - board } & \text { IN THE CUPВOARD - coat is }
\end{array}
$$

2. Воспроизведенные словосочетания содержали лексикосемантические несоответствия:

ПОДЛОЖИТЬ - масла в огонь

IN THE CUPBOARD-clothes

НА ОРБИТУ - вblвод

ONE'S LEG - it costs arm and

3. Парадигматические реакции без грамматической или логической связи:

$$
\begin{array}{ll}
\text { НА ОРБИТУ - космос } & \text { ЧАЯ - вкусный } \\
\text { IN THE CUPBOARD - to serve } & \text { KETTLE OF FISH - }
\end{array}
$$
chips, soup

4. Случаи избыточности языковых средств: вblxod

$$
\text { ПОДЛОЖИТЬ - подножку ВЫЙТИ НА - }
$$

$$
\text { IN THE CUPBOARD - cups BLANKET - duvet }
$$

5. Нестандартные ассоциации:

$$
\text { ПОДЛОЖИТЬ - дискуссию В ФУТЛЯРЕ- }
$$

собачка

$$
\text { FIT - cross, figure A SKELETON- }
$$
stuff/skull 
6. Калькирование русских устойчивых сочетаний на английский язык, говорящее об интерференции родного языка и о безусловном влиянии его культурных реалий у респондентов во втором эксперименте:

$$
\begin{array}{ll}
\text { FOR DUTY - to call } & \text { ARTS - beautiful } \\
\text { SECTOR - prize } & \text { TO PULL - up a trigger }
\end{array}
$$

При выполнении операций восстановления словосочетаний в наших экспериментах обработка стимулов у испытуемых билингвов на двух этапах исследования могла проходить по нейронным путям либо на уровне речевого автоматизма, либо через опосредованное участие механизма родного и второго языка. Как следствие, во втором случае требовалось больше усилий и времени. У респондентов двух упомянутых групп отмечались отличия в силу особенностей перцептивного опыта, накопленного на разных объемах прецедентных текстов и вырабатываемой языковой интуиции. Ассоциативный эксперимент, проведенный с носителями языков при естественном и учебном билингвизме, предоставляет возможность диагностировать меру погружения в лексикофразеологический корпус и культуру изучаемых языков.

\section{ЛИТЕРАТУРА}

1. Аскарова О.Б. Лексико-фразеологическая сочетаемость в психолингвистическом эксперименте // Теория и практика языковой коммуникации: материалы $\mathrm{X}$ Международной научно-методической конференции/ Уфимс.гос.авиац.техн.ун-т.-Уфа: РИК УГАТУ, 2018 - 330 с.

2. Дридзе Т.М. Язык и социальная психология. - М.: Высшая школа, 1980. - 225c.

3. ЗыковаИ.В. Перцепция и фразеологический знак в свете (психо)лингвокультурологического подхода // (Нео)психолингвистикаи (психо)лингвокультурология: новые науки о человеке говорящем. М.: Гносис,2017.- 342 с.

4. Леонтьев А.А. Основы психолингвистики. М.: Смысл; Издательский центр «Академия», 2005.- 288 c.

5. Тер-Минасова С.Г. Словосочетание в научнолингвистическом и дидактическом аспектах. - M.: Издательство ЛКИ, 2007. - 152c.

(C) Аскарова О.Б., 2021 г. 